\title{
Tuning of Microgrid Controllers using Cuckoo Search Algorithm
}

\author{
G. Mallesham*1 , B. Priyadarshini ${ }^{2}$, G. Balaji ${ }^{3}$, Krishna Degavath ${ }^{4}$ \\ 1,2,3,4 Department of Electrical Engineering, University College of Engineering, Osmania University, Hyderabad, \\ INDIA, 500007. \\ Email: malleshamg@yahoo.com
}

\section{Received: $10^{\text {th }}$ Feb 2018, Accepted: $20^{\text {th }}$ March 2018, Published: $30^{\text {th }}$ April 2018}

\begin{abstract}
Microgrid at islanding mode is operated with renewable energy sources like Solar, Wind and non-renewable energy sources like Diesel generator and Battery which supply load to the system efficiently. With the change in load there is frequency deviation and controllers are required. There is a requirement to tune controllers to have optimal utilization of electrical energy and to maintain frequency at desired level. Cuckoo Search Algorithm (CSA) has been implemented to tune the controllers of microgrid. CSA gives optimal solutions in MATLAB using Integral Time Square Error principle (ITSE). The proposed results using CSA in comparison to the trial and error method is improving the steady state response of the considered microgrid, maintaining the system frequency constant. We have proposed a method for tuning the controller to have the frequency of the system at desired level.
\end{abstract}

Keywords: Microgrid, Tuning, Diesel generator, Battery, Cuckoo Search Algorithm.

\section{INTRODUCTION}

Electrical power has been the greatest demand of all times, irrespective of time. This leads to increase in demand, thus emphasizing to continuously meet the increases demand. Main grids meet the loads catering to optimal economic dispatch. A microgrid is a small-scale power grid that can operate independently or in conjunction with the area's main electrical grid [1], [2], [3]. Any small scale localized station with its own power resources, generation and loads and definable boundaries qualifies as a microgrid. These grids being smaller in size are subjected to larger deviations. To overcome this, controllable sources are used to supply power, to balance out the increase in load demand or the reduction in power generation. However due to the delay in the output characteristics of controllable sources, the frequency oscillations are still present in the microgrid. Hence there is a necessity of designing proper controller parameters to controllable sources for optimal utilization of energy and to maintain minimum frequency deviations. In addition, microgrid if integrated with the mega grid will allow bulk consumers to save on electricity costs by using their generators during high peak demand periods when power from the megagrid becomes expensive thereby enhancing the efficiency, reliability and security of large and centralized plants [4]. The various types of small scale generation systems used in a microgrid can be categorized into two groups namely primary sources consisting of solar and wind energy systems and secondary sources (controllable sources) such as diesel generator, fuel cell, aqua electrolyser, battery and flywheel. Keeping view of the above, CSA has been implemented for optimization of all parameters of controllers of microgrid with variations in load demand and power from renewable sources [5]. In this paper, diesel generator and battery are considered, where parameters of Proportional (P), Proportional Integral (PI) and Proportional Integral Derivative (PID) are tuned. This paper elucidates the following. Section II explains the microgrid modeling, its components and their transfer functions. Section III illustrates the Cuckoo Search Algorithm. Simulation analysis and results for various conditions are discussed in Section IV. The conclusions are presented in Section V.

\section{MODELLING OF MICROGRID}

The proposed microgrid block diagram as shown in Fig. (1) consists of wind power source $(250 \mathrm{~kW})$, solar power source $(250 \mathrm{~kW})$, diesel generator $(525 \mathrm{~kW})$ and battery $(15 \mathrm{~kW})$. The sum of power from renewable and controlled sources meets the demand of load.

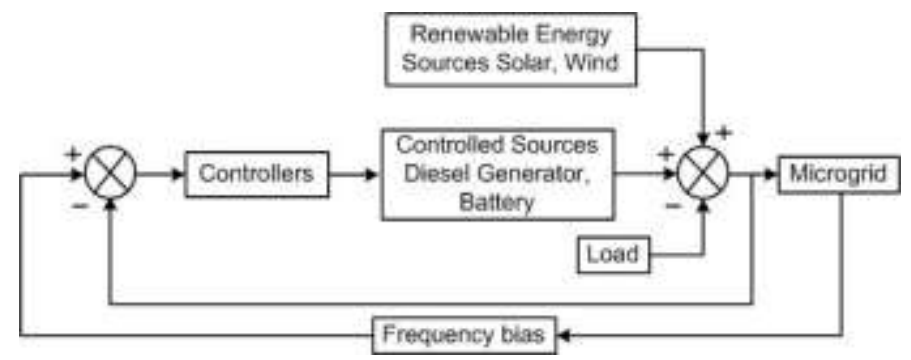

Fig. 1. The block diagram of microgrid with renewable energy sources and controllers. 
The Transfer functions for various sources are:

\section{A. Diesel generator}

A diesel generator is the combination of a diesel engine with an electric generator to generate electrical energy. When power demand fluctuates, the diesel generator varies its output via fuel regulation. On the other hand since this is a synchronous generator, its output voltage can be regulated by controlling the excitation. Diesel generator is represented with a first order transfer function [6] represented in (1).

$$
G_{d g}(s)=\frac{K_{d g}(s)}{1+s T_{d g}(s)}
$$

Where, $\mathrm{K}_{\mathrm{dg}}$ is the gain and $\mathrm{T}_{\mathrm{dg}}$ is the time constant of the diesel generator. The gain and time constant of diesel generator are considered as 1 and 2 sec. respectively.

For the diesel generator, the governor transfer function is represented as (2)

$$
G_{g}(s)=\frac{K_{g}(s)}{1+s T_{d}(s)}
$$

Where $\mathrm{K}_{\mathrm{g}}=1$ and $\mathrm{Tg}=20 \mathrm{sec}$. Therefore the transfer function of a diesel generator will be represented as in (3)

$$
G_{d g}(s)=\frac{K_{d g}(s)}{1+s T_{d g}(s)} \times \frac{K_{g}(s)}{1+s T_{g}(s)}
$$

\section{B. Battery}

A battery is a combination of one or more electro-chemical galvanic cells which converts the chemical energy stored in it into electrical energy. Due to its feasibility and simplicity, the battery has become a common power source for many household and industrial applications, and a big economic industry. The battery is modeled as first order equation as (4)

$$
G_{b}(s)=\frac{K_{b}(s)}{1+s T_{b}(s)}
$$

Where $T_{b}$ is the time constant and $K_{b}$ is the gain of the battery as $0.1 \mathrm{sec}$. and 1 respectively [7].

\section{Microgrid}

The transfer function of microgrid [2] is considered as given in (5)

$$
\frac{\Delta f}{\Delta P}=\frac{1}{M s+D}
$$

where $\mathrm{M}=0.2$ and $\mathrm{D}=0.012$.

Transfer functions for all the components and microgrid are taken from [8]. The assumed microgrid is provided with the $\mathrm{P}$, PI and PID controllers [3]. The frequency bias (B) is explained as follows.

\section{Frequency bias $(B)$}

Considering a microgrid where there are several controllable sources having a control signal, thus to regulate the output power, which is proportional to frequency deviation termed as frequency bias [9]. For a proper functioning of system, the frequency bias characteristics, that are calculated, should match the actual frequency control characteristics.

\section{E.Power and Frequency deviation}

We must control the supply power so as to meet the required load demand since the output power of synchronous generator to avoid fluctuations in frequency. This frequency is controlled by the error in the supply demand $\Delta \mathrm{P}$ which is the difference between power generation $\mathrm{P}_{\mathrm{G}}$ and the power demand $\mathrm{P}_{\mathrm{L}}[8]$.

$$
\Delta f(s)=\frac{f_{s y s}}{2 H s}\left[\Delta P_{G}(s)-\Delta P_{e}(s)\right]
$$

Where

$$
\begin{gathered}
P_{e}(s)=P_{G}(s)-P_{L}(s) \\
P_{G}=P_{\omega}+P_{s}+P_{d g}+P_{b}
\end{gathered}
$$

Generally, the loads are of mixed type like frequency dependant and non-dependant. So speed load characteristics of composite load is approximated by

$$
\Delta P_{e}=\Delta V_{L}+D \Delta \omega
$$

Where the first part of equation (9) is the non-frequency dependant and second part is the frequency sensitive part of the load. Combining equations (6) and (9) we get equation (10).

$\Delta P_{G}-\Delta P_{L}=\left[\frac{2 H}{f_{s y s}} s+D\right] . \Delta f$

Because of the time delay between the system frequency deviation and power deviation, the transfer function for system frequency variation to per unit power deviation is given by

$$
G_{s y s}(s)=\frac{\Delta f}{\Delta P_{e}}=\frac{K}{D+s M}
$$

Where, $\mathrm{K}$ is the system frequency character constant. $M=2 H / f_{\text {sys }}$ and $\mathrm{D}$ are the inertia constant and damping constant of power system respectively. The frequency of the system is $50 \mathrm{~Hz}, \mathrm{D}=0.012 \mathrm{MW} / \mathrm{Hz}, \mathrm{H}=5 \mathrm{sec}, \mathrm{M}=0.2, \mathrm{Td}=$ $20 \mathrm{sec}, \mathrm{Tdg}=2 \mathrm{sec}, \mathrm{Tb}=0.1 \mathrm{sec}$.

\section{CUCKOO SEARCH ALGORITHM}

Cuckoo Search Algorithm was developed by Xin-Shi and Saush Deb in 2009 with the inspiration from obligate brood parasitism of Cuckoo species [10], [11]. It is a nature inspired metaheuristic algorithm which is inspired by the life of a Cuckoo bird. Breeding behavior here combines with cuckoos with levy flight seen in some species of birds. The searching procedure is same 
for Particle swarm optimization and CSA. But CSA using a random walk via levy flight, discovering the new search space and provides the best global result more effectively [12].

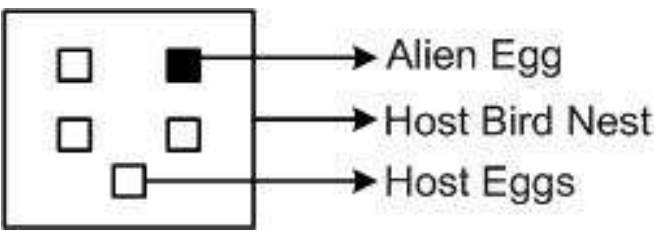

Fig. 2. The analogy of CSA.

Concept of CSA is analogy to the process the Cuckoos bird lays eggs in other bird's nest where the female fertilized eggs are placed in nest of other bird species. When the host bird sees that egg is alien it will either throw the eggs or abandon the nest. If bird does not recognize then the eggs are safe. These eggs are analogous to solutions [13]. The egg arranged by the cuckoo is revealed by the host bird with a possibility $\mathrm{Pa}_{-}[0,1]$. The Fig.2 shows the analogy between the solutions $\left(\mathrm{k}_{\mathrm{p}} ; \mathrm{k}_{\mathrm{i}} ; \mathrm{k}_{\mathrm{d}} ; \mathrm{k}_{\mathrm{f}}\right)$ and the eggs of cuckoo, host nest.

\section{A. Steps for Cuckoo Search Algorithm for microgrid controller gain optimization}

The various steps involved in the algorithm are given below [14].

Step 1: Read the system data and fix the power bounds of the diesel generator, battery and load demand.

Step 2: Initialize the parameters and constants of CSA.

They are nd, no. of nests, N_iter, pa.

Step 3: Generate random nests with the given nests up to 500 nests.

Step 4: Fix iteration count to 1 , iter $=0$ and fitness value

Step 5: Get a cuckoo randomly by levy flights behavior using the equation nest $(i,:)=L b+(U b-L b)$. *rand $(\operatorname{size}(L b))$.

Step 6: Compute the fitness value regarding no. of nests. By using the equation (12), ITSE value is calculated.

$$
I T S E=\int_{0}^{T_{S M}} t \cdot(\Delta f(t))^{2} d t
$$

where $t_{\text {sim }}$ is the simulation time.

Step 7: Take the best fitness value best nest from all the fitness values and take the best nest variable values $\left(\mathrm{k}_{\mathrm{p}}, \mathrm{k}_{\mathrm{i}}, \mathrm{k}_{\mathrm{d}}\right.$ and $\left.\mathrm{k}_{\mathrm{f}}\right)$.

Step 8: Iter=iter+1. Find new nest by using the step size between limits given.
Step 9: Find the fitness value, if $f_{\text {new }}<f_{\min }$ then sends the nest values to the new nest. Next update the best nestwith the new nest values.

Step 10: Keep the best results and check if the iteration counter reaches the maximum iteration. If not then go to step7, else print the best solution obtained.

Step 11: Best nest gives the optimal solution of the voltage, frequency fluctuations and the results are printed.

\section{Step 12: Stop}

The flowchart of the CSA algorithm is shown in Fig.3 [15].

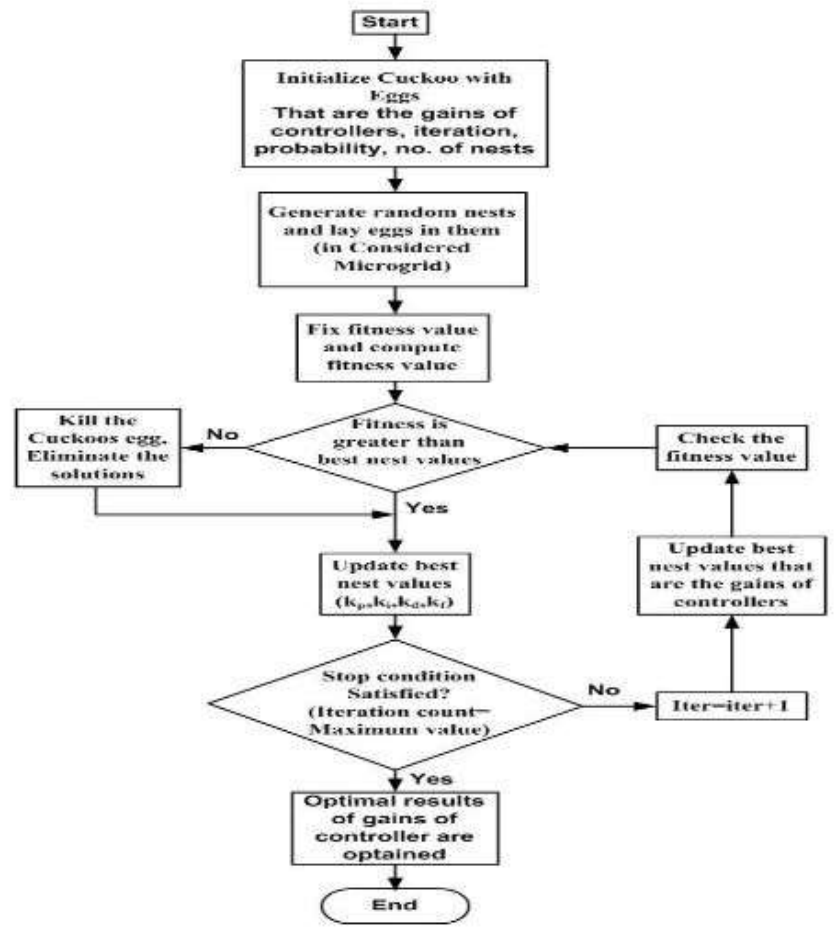

Fig. 3. The flowchart of CSA implemented in microgrid.

\section{SIMULATION ANALYSIS AND RESULTS}

The MATLAB Simulink model of the microgrid is shown in Fig.4. Using CSA the optimization of the parameters of the controllers is done in MATLAB platform. The system consists of wind power source $(250 \mathrm{~kW})$, solar power source $(250 \mathrm{~kW})$, diesel generator $(525 \mathrm{~kW})$ and battery $(15 \mathrm{~kW})$ which experience an increase in load of (12.5 kW) which was supplied by diesel generator and battery. The analysis was done using conventional method (Trial and Error) and CSA method. The system was run for 500 seconds and analysis was carried out. In CSA optimization 1000 iterations was done for 500 solutions (nests) for different probabilities. The system in case I, the diesel generator supplied the increase in load where P, PI, and PID controllers are used. The gains $\mathrm{kp}, \mathrm{ki}, \mathrm{kd}$ and $\mathrm{kf}$ are tuned using Trial and error method, then CSA was implemented and it was found that PID controller gives the best frequency control. In 
case II, PID controller was used since it gave the best control action along with a storage source i.e battery. The total 8 gains ( $\mathrm{kp}, \mathrm{ki}, \mathrm{kd}$ and $\mathrm{kf}$ for diesel generator and battery) are optimized using conventional method and CSA. The optimal ITSE values obtained using CSA methods are better than conventional method.

\section{Case-I: The response of microgrid with increase in load:}

The disturbance in the system causes a sudden increase in load $(12.5 \mathrm{~kW})$ keeping the solar and wind supply constant which is met by the diesel generator. The inertial factor diesel generator causes a delay in giving the output power. The P, PI, and PID controllers are used to control the diesel generator. The gain values of these controllers are optimized using conventional method and then CSA was employed. The CSA optimization has given better results than conventional method and the results are displayed in Table I. The simulation was done for 500sec.

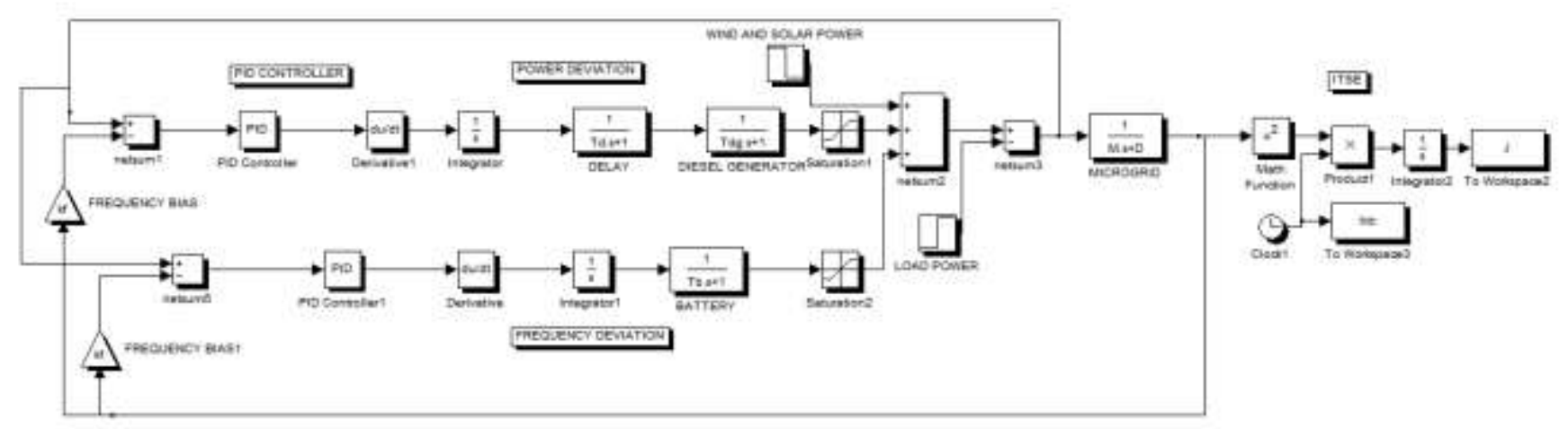

Fig. 4. The MATLAB Simulink block diagram of Microgrid.

TABLE-I PARAMETERS OF CONTROLLERS

\begin{tabular}{|c|c|c|c|c|c|c|}
\hline \multirow[b]{2}{*}{$\begin{array}{l}\text { Perara: } \\
\text { meter: }\end{array}$} & \multicolumn{2}{|c|}{ PControder } & \multicolumn{2}{|c|}{ PI Controller } & \multicolumn{2}{|c|}{ FD Convolier } \\
\hline & $\begin{array}{c}\text { Comentiatad } \\
\text { mechood }\end{array}$ & $\begin{array}{l}\text { Cuchow } \\
\text { Sorosht } \\
\text { Algarition }\end{array}$ & $\begin{array}{l}\text { Converetionst } \\
\text { mechad }\end{array}$ & $\begin{array}{l}\text { Cuicboe } \\
\text { Seaveh } \\
\text { Algorithen }\end{array}$ & $\begin{array}{l}\text { Contrentienst } \\
\text { mothod }\end{array}$ & $\begin{array}{l}\text { Caction } \\
\text { Sowent } \\
\text { Alpurution }\end{array}$ \\
\hline$b$ & onl & 0.701 & 03 & 0.92 & 0.22 & 0.20 \\
\hline$k$ & 0 & 0 & 0.01 & 0.0064 & 002 & 0.0160 \\
\hline 24 & 8 & 0 & 0 & 6 & $I$ & 2.3472 \\
\hline$b$ & 7 & $\frac{2}{2}$ & 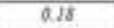 & 0.16 & $\overline{2}$ & 2 \\
\hline$J$ & 6652 & 5813 & 239.6 & 209.29 & 2.592 & 1563 \\
\hline
\end{tabular}

From Fig.5 the $\Delta f$ response for P, PI, PID controllers is observed and found that response was better than P and PI. Thus we decided to use PID controller in case II where storage source like battery is used along diesel generator to supply load.

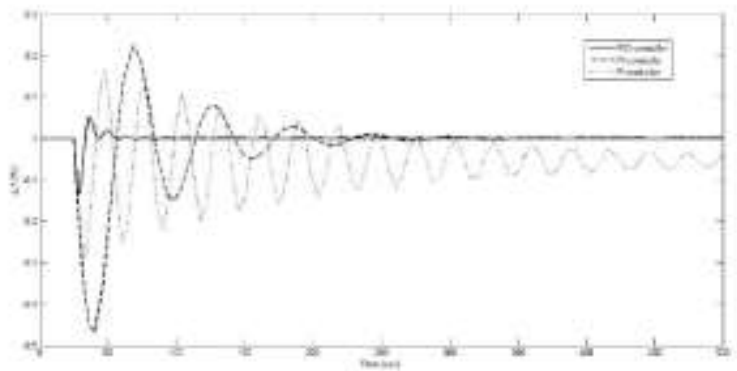

Fig. 5. Comparison of frequency deviation using PID, PI, and P controller for conventional method.
The $\Delta f$ response for the system with PID controller is observed in Fig.6. The system using controller gains optimized using CSA gave better response than conventional method.

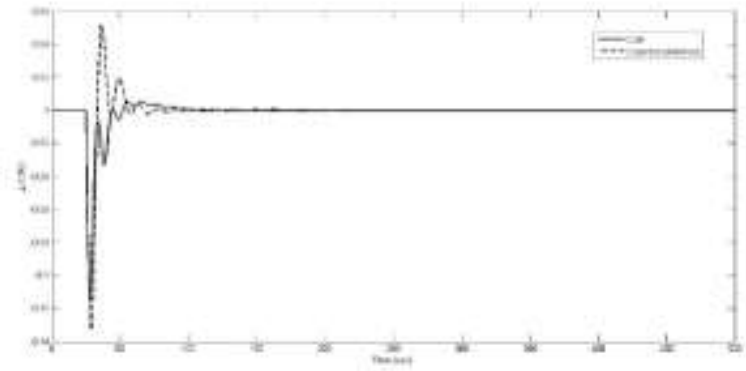

Fig. 6. The change in frequency $(\Delta f)$ response of microgrid using PID controller by conventional and CSA method.

\section{Case-II: The microgrid with energy storage device Battery:}

In case there was a time delay for diesel generator in the transient period, thus a storage source like battery was employed which meets the increase in load $(12.5 \mathrm{~kW})$ caused by a disturbance in the system. The battery supplied power during the transient period. The output of battery becomes zero for steady state where only diesel generator supplies the increase in load. The Fig.7 shows load power $\left(\mathrm{P}_{\mathrm{L}}\right)$, supply power $\left(\mathrm{P}_{\mathrm{S}}\right)$, power given by diesel generator $\left(\mathrm{P}_{\mathrm{dg}}\right)$, power given by battery $\left(\mathrm{P}_{\mathrm{b}}\right)$ and $\Delta f$ response. The controller parameters are optimized using conventional method and CSA and the results are shown 
in Table II. The CSA approach has given better optimized results.

The $\Delta f$ response of the system using PID controller with and without battery is shown in Fig.8. The response for system with battery is having less undershoot and the frequency stabilizes faster than system without battery. Thus, it is advisable to use storage devices like battery with PID controller which gives power to the system instantaneously for transient period and gives no power during steady state.

TABLE-II

PARAMETERS OF PID CONTROLLER
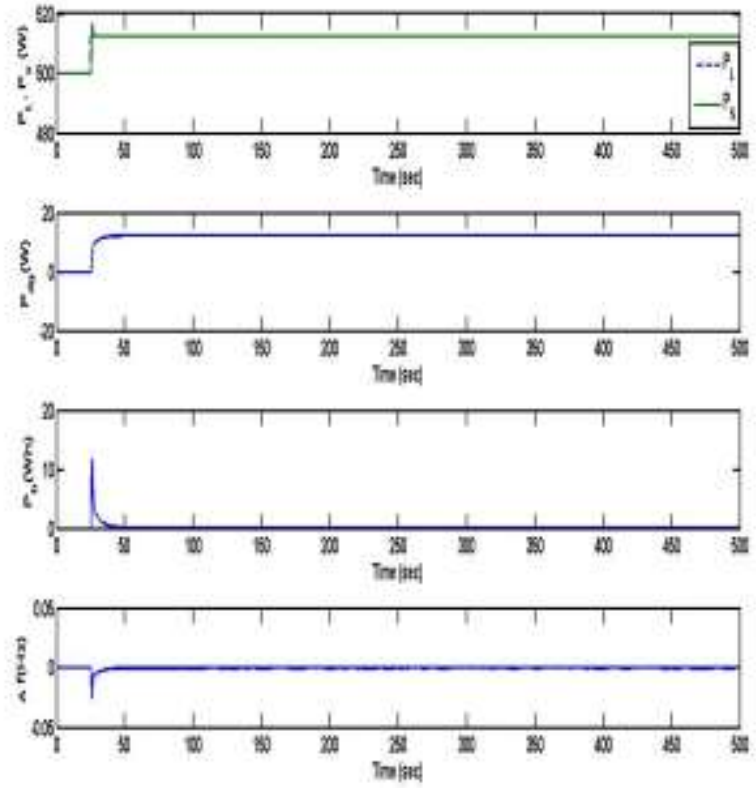

Fig. 7. Response of the microgrid with battery using CSA method.

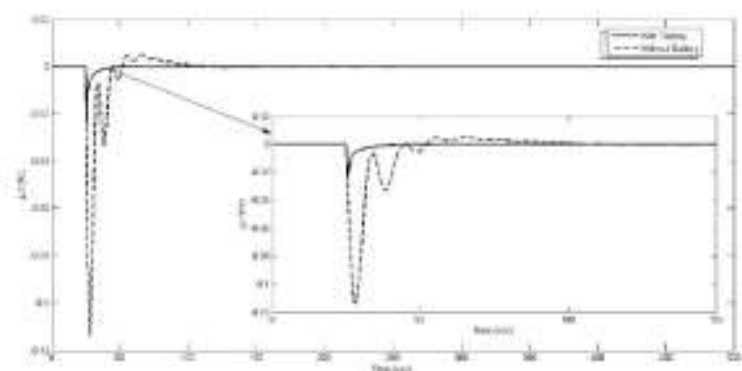

Fig. 8. The change in frequency $(\Delta f)$ response of Microgrid with and without battery using PID controller.

\section{CONCLUSION}

In this paper the optimal values of the controller gains in the microgrid were calculated using the conventional methods and CSA. In this work renewable and non renewable energy sources are used to meet the load. The principle behind the new stratagem adopted is to somehow or other steady the system at the output end and independent of variations in the system due to load fluctuations on all counts. Thus the Cuckoo Search Algorithm has been implemented in the tuning of controller parameters MATLAB atmosphere. By trial and error method, the results achieved were comprehensively compared with Cuckoo Search Algorithm. The resultant conclusion proved that the latter is more efficient and better choice among other optimization techniques.

\section{ACKNOWLEDGEMENT}

Jalli Monica, V. Harini thanks for continous support and essential inputs through out the research and writing of this paper.

\section{REFERENCES}

[1] S. C. S. Chowdhury and P. Crossley, "Microgrids and active distribution networks," Institution of Engineering and Technology, 2009.

[2] T. Senjyu, T. Nakaji, K. Uezato, and T. Funabashi, "A hybrid power system using alternative energy facilities in isolated island," IEEE Transactions on Energy Conversion, vol. 20, no. 2, pp. 406-414, June 2005.

[3] N. Hatziargyriou, H. Asano, R. Iravani, and C. Marnay, "Microgrids," IEEE Power and Energy Magazine, vol. 5, no. 4, pp. 78-94, July 2007.

[4] P. Basak, S. Chowdhury, S. P. Chowdhury, and S. H. nee Dey, "Simulation of microgrid in the perspective of integration of distributed energy resources," in 2011 International Conference on Energy, Automation and Signal, Dec 2011, pp. $1-6$.

[5] M. Bhoye, S. N. Purohit, I. N. Trivedi, M. H. Pandya, P. Jangir, and N. Jangir, "Energy management of renewable energy sources in a microgrid using cuckoo search algorithm," in 2016 IEEE Students' Conference on Electrical, Electronics and Computer Science (SCEECS), Mar 2016, pp. 1-6. 
[6] P. S. Dokopoulos, A. C. Saramourtsis, and A. G. Bakirtzis, "Prediction and evaluation of the performance of wind-diesel energy systems," IEEE Transactions on Energy Conversion, vol. 11, no. 2, pp. 385-393, Jun 1996.

[7] M. Gopal and V. Singh, "Control Systems Engineering” pp. 656-656, 1976.

[8] G. Mallesham, S. Mishra, and A. N. Jha, "Maiden application of ziegler-nichols method to agc of distributed generation system," in 2009 IEEE/PES Power Systems Conference and Exposition, March 2009, pp.1-7.

[9] M. L. D. Ngo, R. L. King, and R. Luck, "Implications of frequency bias settings on agc," in Proceedings of the TwentySeventh Southeastern Symposium on System Theory, Mar 1995, pp. 83-86.

[10] X. S. Yang and S. Deb, "Cuckoo search via levy flights," in 2009 World Congress on Nature Biologically Inspired Computing (NaBIC), Dec 2009, pp. 210-214.

[11] X.-S. Yang and S. Deb, "Cuckoo search: recent advances and applications", Neural Computing and Applications, vol. 24, no. 1, pp. 169-174,Jan 2014.

[12] M. Modiri-Delshad, S. S. Taheri, S. J. Seyed-Shenava, and N. A. Rahim, "Optimal generation scheduling in microgrids by cuckoo search algorithm," in 3rd IET International Conference on Clean Energy and Technology (CEAT) 2014, Nov 2014, pp. $1-5$.

[13] D. N. Vo, P. Schegner, and W. Ongsakul, "Cuckoo search algorithm for non-convex economic dispatch," IET Generation, Transmission Distribution, vol. 7, no. 6, pp. 645-654, June 2013.

[14] S. Vasanthakumar, N. Kumarappan, R. Arulraj, and T. Vigneysh, "Cuckoo search algorithm based environmental economic dispatch of microgrid system with distributed generation," in 2015 International Conference on Smart Technologies and Management for Computing, Communication, Controls, Energy and Materials (ICSTM), May 2015, pp. 575-580. 